BULLETIN Bulletin hispanique

HISPANIQUE Université Michel de Montaigne Bordeaux

118-1 | 2016

La Guerre Civile espagnole aujourd'hui (1936-2016)

\title{
De quemas y purgas
}

el bibliocausto franquista durante la Guerra Civil

\section{Ana Martínez Rus}

\section{(2) OpenEdition \\ Journals}

Edición electrónica

URL: http://journals.openedition.org/bulletinhispanique/4299

DOI: 10.4000/bulletinhispanique.4299

ISSN: 1775-3821

Editor

Presses universitaires de Bordeaux

\section{Edición impresa}

Fecha de publicación: 15 julio 2016

Paginación: 177-194

ISBN: 979-10-300-0058-0

ISSN: 0007-4640

Referencia electrónica

Ana Martínez Rus, « De quemas y purgas », Bulletin hispanique [En línea], 118-1 | 2016, Publicado el 15

julio 2019, consultado el 10 septiembre 2019. URL : http://journals.openedition.org/

bulletinhispanique/4299; DOI : 10.4000/bulletinhispanique.4299 


\title{
De quemas y purgas: el bibliocausto franquista durante la Guerra Civil
}

\author{
Ana Martínez Rus ${ }^{1}$ \\ Universidad Complutense de Madrid
}

L'article analyse la destruction par les franquistes du patrimoine bibliographique espagnol pendant la Guerre Civile. L'autodafé des livres, l'épuration des fonds du marché éditorial et des librairies et l'expurgation des bibliothèques étaient devenus un impératif prioritaire pour les autorités militaires. Le but était d'éliminer toutes les publications pernicieuses qui avaient empoisonné l'âme et l'esprit des Espagnols.

Mot-clés: bibliocauste, Guerre Civile espagnole, Publishers, franquisme, épuration.

En este artículo se analiza la destrucción del patrimonio bibliográfico español por el bando franquista durante la guerra civil. La quema de libros, la depuración de fondos del mercado editorial y librero, y el expurgo de bibliotecas se convirtieron en una necesidad imperiosa para las autoridades militares. El objetivo era eliminar todas las publicaciones disolventes que habían envenenado la mente y el alma de los españoles.

Palabrasclave: bibliocausto, Guerra Civil española, editoriales, franquismo, depuración.

The destruction of the Spanish bibliographic heritage by the pro-Franco side during the Spanish Civil War is discussed in this article. The burning of books, the purging of the publishing market and bookseller funds and the weeding of libraries became an imperative for the military authorities. The target was to eliminate every pernicious publication that had poisoned the mind and soul of the Spanish.

Keywords: bibliocaust, spanish Civil War, publishers, franco dictatorship, purge.

1. Este trabajo se inserta en el Proyecto de Investigación del Ministerio de Economía y Competitividad, HAR 2014-51883-P: “Scripta in itinere". Discursos, formas y apropiaciones de la cultura escrita en espacios públicos desde la Primera Edad Moderna a nuestros días", dirigido por Antonio Castillo Gómez.

Bulletin Hispanique, Tome 118, nº 1 - juin 2016 - p. 177-194. 


\section{EXPOLIOS Y HOGUERAS}

De la misma manera que en la España de Franco fueron asesinadas miles de personas, se destruyeron millones de publicaciones mediante hogueras purificadoras. En cada plaza de los pueblos se organizaron quemas públicas del veneno escrito como acto fundacional del nuevo Estado. Asimismo se trituraron otros tantos kilos de libros con guillotinas a fin de convertirlos en pasta de papel de los nuevos títulos imperiales y de mártires que se editaron durante la contienda y en la inmediata posguerra. El fuego resultó más simbólico y efectivo en la eliminación de las ideas del enemigo que la afilada hoja de metal en la aniquilación de páginas. Con las teas incandescentes, toneladas de volúmenes fueron reducidos a cenizas, quedando solo el olor a papel y cartón quemado y el polvo de tanta infamia. Aunque menos poética, la guillotina permitía reaprovechar las virutas de papel en pasta para nuevos ejemplares. La causa para esta pena tan severa se debía a que esas páginas eran para las autoridades militares, eclesiásticas y civiles que se sublevaron el 18 de julio de 1936, las responsables de la guerra civil. Los textos y las ideologías de esos libros eran culpables. El «alzamiento» que había salvado España del comunismo, el ateísmo y la masonería también había librado a los españoles de esos contenidos ponzoñosos. De este modo se atajó la infección que se había extendido por todo el país: extirpando los malos libros y sus ideas nocivas para proteger así las mentes y las almas de los buenos patriotas.

El franquismo fue un régimen represivo de exclusión ideológica y social ${ }^{2}$. La represión fue sistémica porque afectó a todos los aspectos de la sociedad española durante casi cuarenta años. La represión cultural, basada en la quema de publicaciones, la censura y en el control de la información, formó parte de la represión generalizada de los militares sublevados y fue un capítulo más de la violencia ejercida por el régimen franquista. El objetivo era limpiar y purificar el país de las ideas subversivas que habían adulterado las esencias españolas. Se trataba de suprimir el pensamiento de los vencidos e imponer el de los vencedores.

La censura, en su versión más dura, recogida en la eufemística ley de Prensa de 1938, formaba parte del ciclo represivo contra el libro, era un eslabón más, pero no el único ni el más grave. Primero se destruyó la oferta editorial y bibliotecaria del país quemando y guillotinando libros, luego se expurgaron y depuraron los fondos bibliográficos de los anaqueles de las bibliotecas, de los almacenes de las editoriales y de los escaparates de las librerías. Después se

2. Julio Aróstegui Sánchez, «Opresión y pseudo-juricididad: de nuevo sobre la naturaleza del franquismo", en Bulletin d'histoire contemporaine de l'Espagne, Université de Provence, núm. 24, 1996, pp. 31-46; y "Una dictadura "sui generis": ideología de exclusión y aparato represivo", en A. Segura, A. Mayayo y T. Abelló (dirs.), La dictadura franquista. La institucionalizació d'un règim, Barcelona, Universitat de Barcelona, 2012, pp. 423-456. 
estableció la censura previa para controlar la oferta nacional e internacional e impedir que salieran al mercado títulos prohibidos y perjudiciales, y por último se publicaron textos sanos de acuerdo con el nuevo decálogo franquista, en muchos casos con fines propagandísticos. La censura por sí sola no tenía sentido, o al menos resultaba insuficiente sin los otros elementos de protocolo punitivo.

La legislación y las acciones de los militares rebeldes fueron muy explícitas y expeditivas al respecto desde el comienzo de la contienda. No bastaba solo con destruir los títulos presentes, ni siquiera con purgar los catálogos de las bibliotecas, y tampoco era suficiente con recluir obras en salas especiales para la consulta restringida tan solo a especialistas, ni con prevenir la oferta científica y literaria con la censura, ni con sustituir toda esa producción bibliográfica malévola por otra complaciente con el régimen y la Iglesia. Si solo se atendía al patrimonio bibliográfico existente podrían aparecer nuevas obras perniciosas, y si solo se prohibían los nuevos títulos podrían circular todas las obras publicadas desde los inicios del liberalismo. Así que era tan necesario ocuparse de las estanterías de las bibliotecas públicas y privadas, y de los fondos editoriales, de librerías y de quioscos, como controlar los catálogos y novedades editoriales de sellos nacionales y extranjeros. Llamas y cuchillas acabaron con toneladas de obras, pero posteriormente y a la vez se fiscalizaron fondos para apartar muchos títulos al gran público, reservándolos solo a usuarios autorizados y cualificados. Una vez limpia la patria de esa podredumbre intelectual, se establecieron los filtros necesarios para impedir la aparición de esos libros o de otros similares e igualmente peligrosos. De este modo se procuró no dejar resquicio para que se colaran las ideas de la anti-España. Los libros y las ideologías subversivas habían encolerizado a millones de personas, provocando la muerte, el asesinato, la destrucción, el saqueo... En definitiva eran los primeros y directos culpables de la gran hecatombe que vivió el país. Por todo ese mal causado, el castigo debía ser ejemplar y contundente para esos libros criminales y delincuentes. Su aniquilación formó parte del mismo sistema represivo que eliminó personas y privó de libertad a otras muchas.

Desde los primeros días de julio de 1936 los militares sublevados actuaron con mucha violencia con todos aquellos que se opusieron a sus objetivos y al mismo tiempo se emplearon con saña contra la cultura impresa en todas las localidades que iban conquistando ${ }^{3}$. Se convirtió en una necesidad acabar con todas las obras que habían inculcado el mal y la revolución en las mentes de los españoles atentando contra el orden social, la tradición, la Iglesia y el Ejército. El libro era peligroso y había que eliminarlo. De este modo se perseguía acabar con la democracia, los derechos sociales y laborales, la reforma agraria y la libertad de expresión. Así, a los pocos días de entrar en Madrid y antes de celebrar el desfile de la Victoria, se celebró la Fiesta del Libro de 1939 realizando una quema pública de libros en la Universidad Central de la capital. 
Auto de fe en la U. Central. Los enemigos de España fueron condenados al fuego.

El Sindicato Español Universitario celebró el domingo la Fiesta del Libro con un simbólico y ejemplar auto de fe. En el viejo huerto de la Universidad Central -huerto desolado y yermo por la incuria y la barbarie de tres años de oprobio y suciedad- se alzó una humilde tribuna, custodiada por dos grandes banderas victoriosas. Frente a ella, sobre la tierra reseca y áspera, un montón de libros torpes y envenenados [...] Y en torno a aquella podredumbre, cara a las banderas y a la palabra sabia de las Jerarquías, formaron las milicias universitarias, entre grupos de muchachas cuyos rostros y mantillas prendían en el conjunto viril y austero una suave flor de belleza y simpatía.

El catedrático de Derecho, Antonio Luna, en su disertación afirmó:

Para edificar a España una, grande y libre, condenados al fuego los libros separatistas, los liberales, los marxistas, los de la leyenda negra, los anticatólicos, los del romanticismo enfermizo, los pesimistas, los pornográficos, los de un modernismo extravagante, los cursis, los cobardes, los seudocientificos, los textos malos y los periódicos chabacanos. E incluimos en nuestro indice a Sabino Arana, Juan Jacobo Rousseau, Carlos Marx, Voltaire, Lamartine, Máximo Gorki, Remarque, Freud y al Heraldo de Madrid. Prendido el fuego al sucio montón de papeles, mientras las llamas subían al cielo con alegre y purificador chisporroteo, la juventud universitaria, brazo en alto, cantó con ardimiento y valentía el himno "Cara al sol" [la cursiva es mía $]^{4}$.

Este fragmento del artículo de prensa refleja perfectamente las actuaciones realizadas respecto al libro durante la guerra civil y señala la política del Nuevo Estado en relación con la letra impresa. Aparecen los falangistas viriles, las jóvenes con mantilla en la universidad madrileña para quemar a Rousseau españolizado, Marx, Freud, Gorki o Lamartine junto con los ejemplares del periódico El Heraldo de Madrid. La combinación es selecta y diversa, aunque atendiendo a la clasificación hecha todos los libros debían acabar en la hoguera. Curiosa manera de celebrar el Día de Libro, imitando las quemas públicas de libros de los nazis. Estas prácticas inquisitoriales, más propias del Santo Oficio que de un sistema político del siglo XX, fueron muy comunes durante la guerra civil y en la inmediata posguerra. De hecho nos encontraremos con numerosos testimonios y declaraciones de jerarcas del régimen que atestiguan estas piras purificadoras.

Desde los primeros días del golpe militar se convirtió en una auténtica obsesión la eliminación de los textos perniciosos que habían inoculado el mal en las mentes de los españoles. Así en los primeros meses de la contienda las operaciones se centraron en destrucciones e incautaciones de libros, junto con la depuración de bibliotecas públicas y privadas. Al mismo tiempo muchos bibliotecarios, editores y libreros fueron fusilados. El director de la casa Nós, Ángel Casal, y el librero Rogelio Luque, entre otros, corrieron la misma suerte que las publicaciones que producían y vendían. Rogelio Luque, que ejercía el comercio de librería desde 1917 en la calle Gondomar de Córdoba, fue fusilado el 16 de agosto de $1936^{5}$. Juana Capdevielle, bibliotecaria de la Facultad de

4. «Auto de fe en la Universidad Central» en $Y a, 2$ de mayo de 1939, p. 2.

5. Francisco Moreno Gómez, La guerra civil en Córdoba (1936-1939), Madrid, Alpuerto, p. 307. 
Filosofía y Letras de la Universidad de Madrid, fue asesinada el 18 de agosto de 1936 en Rábade (Lugo) estando embarazada de su primer hijo a los treinta años de edad'.

El periódico Arriba España en su primer número de 1 de agosto de 1936, incitaba a la destrucción de libros: «iCamarada! Tienes obligación de perseguir al judaísmo, a la masonería, al marxismo y al separatismo. Destruye y quema sus periódicos, sus libros, sus revistas, sus propagandas. ¡Camarada! ¡Por Dios y por la patria!». Su director fue el clérigo, Fermín Idurziaga, que acabó siendo Jefe Nacional de Prensa y Propaganda. Fue tal el entusiasmo y celo en la destrucción de libros en los domicilios particulares que el mismo periódico en noviembre de 1936 pidió mesura y que se no se actuara en las bibliotecas privadas. Estas prácticas recordaban al régimen hitleriano, a la quema sistemática de publicaciones en Alemania organizada por el Ministro de Propaganda, Joseph Goebbels. El 10 de mayo en la plaza de la Ópera de Berlín ardieron entre 20.000 y 25.000 ejemplares, entre los que se encontraban títulos de Stefan Zweig, Voltaire, Einstein, Freud, Engels, Remarque, Heinrich Mann, André Gide, Romain Rolland o H. G. Wells entre otros. Otras treinta hogueras similares se sucedieron entre el 10 de mayo y el 21 de junio de 1933 en otras ciudades alemanas. El gran impacto que causó la destrucción nazi en 1933 llevó a la revista estadounidense Time a calificarla de bibliocausto y la revista neoyorkina, Newsweek, como holocausto de libros ${ }^{7}$. En la España franquista también puede hablarse de un fenómeno similar, de bibliocausto, o al menos de una bibliofobia desatada, en palabras de José Andrés de Blas ${ }^{8}$. Pero la destrucción del patrimonio bibliografíco español es mucho menos conocido que el nazi y apenas existe bibliografía al respecto9. El régimen franquista se encargó posteriormente de borrar este capítulo negro de su historia. En este sentido el historiador Francisco Espinosa decía en 2009 que «la historia de la destrucción de bibliotecas por el fascismo español está por hacer ${ }^{10}$. Extirpar,

6. María Cristina Gállego Rubio, Juana Capdevielle San Martín. Bibliotecaria de la Universidad Central, Madrid, Universidad Complutense, 2010.

7. Fernando Fernández Báez, Historia Universal de la destrucción de libros. De las tablillas sumerias a la guerra de Irak, Barcelona, Destino, 2004, pp. 218-227. Lucien Xavier Polastron, Libros en llamas. Historia de la interminable destrucción de bibliotecas, México, Fondo de Cultura Económica, 2007.

8. José Andrés de Blas, «La guerra civil española y el mundo del libro: censura y represión cultural (1936-1937)», en Represura, http://www.represura.es/, núm. 1, septiembre de 2006, pp. 1-78.

9. Vid. Ana Martínez Rus, La persecución del libro. Hogueras, infiernos y buenas lecturas (19361951), Gijón, Trea, 2014; "Expolios, hogueras, infiernos. La represión del libro», Represura, http://www.represura.es/, $\mathrm{n}^{\circ}$ 8, febrero 20013; «La represión cultural: libros destruidos, bibliotecas depuradas y lecturas vigiladas», en J. Aróstegui (coord.), Franco: la represión como sistema, Barcelona, Flor del Viento, 2012, pp. 365-415. Y Ana Martínez Rus y Verónica Sierra Blas, «Libros culpables: hogueras, expurgos y depuraciones. La política represiva del franquismo, 1936-1939", en A. Segura, A. Mayayo y T. Abelló (dirs.), La dictadura franquista, op. cit, pp. 143-157.

10. Francisco Espinosa en el prólogo del libro de Fernando Romero Romero, La cultura y la 
purificar, borrar, depurar, limpiar, quemar, destruir, purgar, eliminar, liquidar, exterminar, etcétera, son los verbos que mejor definen la labor de los sublevados en la guerra y durante la posterior dictadura en relación con el patrimonio bibliográfico del país ${ }^{11}$.

El cenetista Manuel Pérez recuerda que el primer día del levantamiento militar en la isla de Mallorca: «[...] se inició el asalto a las organizaciones obreras y a los locales donde tenían su residencia las agrupaciones políticas de izquierdas. Nada escapó a la furia vandálica de las hordas fascistas. Después de destrozarlo todo [...], recordando los autos de fe de la "santa Inquisición", hicieron hogueras con los libros que encontraron en las bibliotecas", [la cursiva es mía] ${ }^{12}$. Las quemas públicas de libros en La Coruña también fueron habituales, frente al edificio del Real Club Náutico, en el muelle, según recogió el periódico, $E l$ Ideal Gallego, en agosto de 1936: «A orillas del mar, para que el mar se lleve los restos de tanta podredumbre y de tanta miseria, la Falange está quemando montones de libros y folletos de criminal propaganda comunista y antiespañola y de repugnante literatura pornográfica», [la cursiva es mía] ${ }^{13}$. Recordemos que el gobernador civil de La Coruña y esposo de la bibliotecaria Juana Capdevielle, Francisco Pérez Carballo, había sido asesinado en los primeros días del golpe, el 24 de julio de 1936. Su sustituto, el teniente coronel de la Guardia Civil, Florentino González Vallés, ordenó en agosto que las bibliotecas de los centros obreros clausurados fueran examinadas, "procediéndose a la quema de toda prensa, libros y folletos de propaganda de ideas extremistas, así como la de temas sociales y pornográficos, y en general todos aquellos que, de un modo más o menos claro encierren propaganda reñida con la buena moral, así como los que combatan la religión cristiana y católica, base del sentimiento religioso del pueblo español ${ }^{14}$. Se convirtió en una auténtica obsesión la destrucción de las publicaciones, la quema pública de libros como otra forma más de violencia ejercida contra los «hijos de Caín» ${ }^{15}$. Asimismo en el mismo mes de agosto del 36 en Vigo «en la Plaza de Armas fueron quemados en la noche del domingo, libros pornográficos y de ideas extremistas, que habían sido recogidos por la

revolución. República y guerra civil en Prado del Rey, Junta de Andalucía/Ayuntamiento de Prado del Rey/CGT, 2011, p. 17.

11. Vid. el testimonio y la experiencia del inspector de bibliotecas, Juan Vicéns de la Llave: «Recientemente he podido tener noticias de la suerte de algunas bibliotecas que actualmente se encuentran en zona rebelde. La historia es simple, la misma: el bibliotecario es fusilado, los libros quemados, todos los que participaron en su organización son fusilados o perseguidos», en España viva. El pueblo a la conquista de la cultura, Madrid, VOSA, 2002, p. 55. El texto original se publicó en francés en 1938.

12. Vid. Manuel Pérez, Cuatro meses de barbarie. Mallorca bajo el terror fascista, Valencia, CNT-FAI, 1937, p. 11.

13. En El Ideal Gallego, 18 de agosto de 1936, y Carlos Fernández Santander, Historia de las Librerias Coruñesas 1936-1996, Arenas Librería, 1996, pp. 82-83.

14. En Boletin Oficial de la Provincia de La Coruña, La Coruña, 14 de agosto de 1936.

15. Así denominó el obispo de Salamanca Enrique Plá y Deniel a los comunistas y anarquistas en su famosa carta pastoral, «Las dos ciudades» de 30 de septiembre de 1936. 
policía. Anoche se verificó en la plaza de Amboage un acto análogo» ${ }^{16}$. Incluso la posesión de libros comunistas y pornográficos fueron cargos agravantes en las causas militares contra ciudadanos como Ramón Romero Castro y Vicente Díaz Veiga en el Ferrol ${ }^{17}$. En otros casos eran los propios republicanos quienes acusaban a las publicaciones de sus actuaciones. Así en la carta de un carabinero fusilado en julio de 1938 afirmaba: «Si yo he sido un asesino y muero como tal ha sido por el estrago que en mi ha ocasionado el Heraldo de Madrid ${ }^{18}$. Este ataque y justificación exculpatoria del reo recogía perfectamente la convicción de los militares y propagandistas franquistas sobre la culpabilidad y responsabilidad de las publicaciones en el conflicto bélico.

En muchas bibliotecas escolares también se destruyeron ejemplares por orden de la Comisión nombrada por la alcaldía después de los días siguientes al golpe militar como la de Paredes de Nava en Palencia, aparte de los destrozos que ocasionaron el alojamiento de las tropas ocupantes, instaladas en escuelas y bibliotecas ${ }^{19}$. El fuego se convirtió en símbolo de lo viejo, de lo negativo, de lo malo que había que eliminar, y al mismo tiempo de la purificación, de la limpieza, de lo nuevo, de lo bueno que había que preservar y difundir :

Significa que el libro y la prensa mal inspirados -verdaderamente estupefacientes del alma- habían intoxicado ya la conciencia colectiva, aletargándola. Significa, en fin, que el Enemigo estaba a punto de conseguir su objeto, de corromper la médula de un gran pueblo. Guerra, por tanto, al libro malo. Imitemos el ejemplo que nos brinda Cervantes en el capítulo sexto de su Obra inmortal. Y que un día próximo se alcen en las plazas públicas de todos los pueblos de la nueva España las llamas justicieras de fogatas, que al destruir definitivamente los tóxicos del espiritu almacenados en librerías y bibliotecas, purifiquen el ambiente, librándolo de sus mismas contaminadores. ¡Arriba España! ¡Viva Franco! ¡Viva España!», [La cursiva es mía $]^{20}$.

El falangista Fernando García Montoto fue uno de los más furibundos en sus declaraciones públicas a favor de la quema de libros, folletos y periódicos y en la eliminación física de sus autores ${ }^{21}$. En la misma línea apuntó el Rector de la Universidad de Zaragoza, Gonzalo Calamita, que un artículo titulado, «iEl peor estupefaciente!», hacía referencia al «libro sectario» que poblaba las «bibliotecas criminales» de todo el país. Por este motivo argumentaba que «el fuego purificador, es la medida radical contra la materialidad del libro» ${ }^{22}$.

16. En El Pueblo Gallego, Vigo, 18 de agosto de 1936.

17. Emilio Grandío (ed.), Anos de odio. Golpe, represión e guerra civil na provincia da Coruña (1936-1939), A Coruña, Diputación da Coruña, 2007, pp. 245-246.

18. José Andrés-Gallego y Antón M. Pazos, Archivo Gomá. Documentos de la Guerra Civil. Julio-Septiembre de 1938, Madrid, CSIC, pp. 140-141.

19. José Andrés de Blas, «El proceso de depuración de los fondos de las bibliotecas escolares (1ªrte)» en Represura, http://www.represura.es/, nº 7, febrero de 2011.

20. Fernando García Montoto, En el amanecer de España, Tetuán, Imprenta Hispania, 1938, p. 89. El título del capítulo tampoco tiene desperdicio: "Estupefacientes" del alma (El libro y la prensa mal inspirados, germen del odio y de la destrucción revolucionaria)».

21. Ibidem, p. IX.

22. Vid. Boletín de Educación de Zaragoza, n 3, diciembre-noviembre, 1936. 
Cabe destacar el constante recurso a la obra cervantina por parte de los publicistas del franquismo para justificar las innumerables hogueras de publicaciones, en concreto al famoso capítulo donde se quemaban los libros de caballería de Don Quijote. Era un alegato perfecto remontarse a las páginas de la más insigne obra en castellano para demostrar que era una acción justa y necesaria. De hecho se comparaba la condición de soldado de Cervantes, que luchó contra los enemigos de España en la cruzada de Lepanto, con el ejército del invicto Franco que derrotó al bolchevismo asiático. Asimismo la influencia de las tesis del Concilio de Trento en el escritor alcalaíno permitía establecer un paralelismo con la defensa del catolicismo que realizaron las autoridades franquistas.

A los seis días del golpe de estado contra el gobierno republicano se formó la Junta de Defensa Nacional, formada exclusivamente por militares, para gestionar el territorio que quedó bajo su control. La primera disposición de la Junta sobre la depuración de bibliotecas y el control de la lecturas fue la Orden del 4 de septiembre, donde se acusaba al Ministerio de Instrucción republicano de haber difundido obras marxistas entre la infancia. Por ello era necesario hacer desaparecer esas publicaciones y obligaba a la incautación y destrucción de las mismas, autorizando sólo «aquellas cuyo contenido responda a los sanos principios de la Religión y de la Moral, y que exalten con su ejemplo el patriotismo de la niñez». El Decreto de 13 de septiembre que declaraba fuera de la ley a las personas, partidos y agrupaciones políticas que formaron el Frente Popular, también incluía la incautación de sus bienes y bibliotecas. Aunque una Orden posterior, del 10 de junio de 1938, disponía que estas colecciones debieran quedar bajo el control de los funcionarios del Cuerpo de Archivos, Bibliotecas y Museos, en la realidad fueron la Guardia Civil, los Ayuntamientos y Falange quienes se ocuparon de estos fondos.

El 1 de octubre de 1936 se constituyó por Ley la Junta Técnica del Estado, y una de las comisiones dependientes de ella fue la de Cultura y Enseñanza, presidida por José Ma Pemán, y con Enrique Suñer Ordoñez como vicepresidente, encargada de purgar el patrimonio bibliográfico nacional. Esta misma comisión se encargó de la depuración del magisterio y del profesorado universitario. El 23 de diciembre de 1936 se promulgó un Decreto que declaraba ilícitas todo tipo de publicaciones socialistas, comunistas, libertarias, pornográficas y disolventes. El preámbulo de este decreto era toda una declaración programática de las autoridades militares ya que justificaba la necesidad de aplicar medidas represivas respecto a la letra impresa. Además consideraban que las ideas subversivas habían calado en un público no preparado y eran las responsables directas y últimas del conflicto civil. Según su criterio la mayoría de la población se había dejado embaucar por estos textos y, por tanto, había que perseguirlos y suprimirlos de los establecimientos públicos y privados:

Una de las armas de más eficacia puesta en juego por los enemigos de la Patria ha sido la difusión de la literatura pornográfica y disolvente. La inteligencia dócil de la juventud y la ignorancia de las masas fueron el medio propicio donde se desarrolló el 
cultivo de las ideas revolucionarias y la triste experiencia de este momento histórico demuestra el éxito del procedimiento elegido los enemigos de la Religión, de la civilización, de la familia y de todos los conceptos en que la sociedad descansa.

La enorme gravedad del daño impone remedio pronto y radical. Se ha vertido mucha sangre y es ya inaplazable la adopción de aquellas medidas represivas y de prevención que aseguren la estabilidad de un nuevo orden jurídico y social y que impida además la repetición de la tragedia, [la cursiva es mía].

Por último esta disposición legal contemplaba medidas expeditivas contra aquellos que incumplieran su aplicación. Las infracciones implicaban una multa de 5.000 pesetas, y si se reincidía la multa aumentaría un quíntuplo y además llevaba aparejada la pérdida de empleo público, o bien la inhabilitación del sancionado para el ejercicio de la industria editorial o de librería, así como el cierre del respectivo establecimiento. Cabe destacar las similitudes entre este Decreto y un Bando anterior de Queipo de Llano, Jefe del Ejército de Operaciones del Sur, sobre recogida y expurgo de libros. La persecución de los sublevados a los libros explica que uno de los primeros Bandos de Queipo, el número 25, abordase la ilicitud de impresos pornográficos y disolventes, así como la entrega de los mismos a las autoridades militares y el castigo a los infractores ${ }^{23}$. El Bando, de 4 de septiembre de 1936, constaba de cinco artículos. En el preámbulo se acusaba directamente a la masonería, el judaísmo y al marxismo de la propagación de estas obras, en vez de a los enemigos de la religión, de la civilización y de la familia como en la Orden de diciembre. En el primer artículo del Bando se declaraban ilícitos la producción, comercio, circulación y tenencia de libros, periódicos y todo tipo de impresos pornográficos, socialistas, comunistas, libertarios y disolventes en general. El segundo obligaba a todos los establecimientos editoriales, a las librerías y a los kioscos radicados en la Segunda División Orgánica a entregar todas las publicaciones prohibidas a las autoridades militares en un plazo improrrogable de 48 horas. Sorprende que en el artículo tercero se hiciera extensiva esta obligación a todos los particulares, a entidades públicas y a corporaciones privadas. De este modo la posesión de este tipo de literatura constituía un delito en la Andalucía rebelde. Aunque en el artículo cuarto se contemplaba que las bibliotecas oficiales y los particulares que necesitasen estos textos por motivos profesionales quedaban exentas de esta prohibición, se señalaba la necesaria autorización de los militares para la posesión de dichos títulos, y siempre que «su acendrando patriotismo y amor al orden, no ofrezcan sospechas de que puedan hacer uso ilícito de los mismos». En el último artículo se fijaban las multas económicas y sanciones a todos los que no cumpliesen con este Bando, mayores que las recogidas en el Decreto posterior, ya que alcanzaban hasta las 10.000 pesetas $^{24}$. Otra diferencia entre

23. Bandos y órdenes dictados por el Excmo. Sr. D. Gonzalo de Queipo de Llano y Sierra, General Jefe de la $2^{a}$ División Orgánica y del Ejército del Sur. Comprende desde la declaración del estado de guerra el 18 de julio de 1936 hasta el fin de febrero de 1937, Sevilla, Imprenta Municipal, 1937, pp. 24-25.

24. José Luis Rubio Mayoral, «La depuración de la cultura popular. La Universidad y el Ateneo de Sevilla en la censura de libros durante la guerra civil» en E. BELENGUER CALPE y 
el Bando de Queipo y el Decreto de 23 de diciembre era que en este último se indicaba que las publicaciones debían entregarse a la autoridad civil, en vez de a la militar, aunque esta a su vez debía comunicárselas a los responsables militares. Y también se establecía que los agentes depositarían los libros en las respectivas bibliotecas universitarias, o en las provinciales, o bien en el archivo de Hacienda, según los casos, pero no en instalaciones militares.

Atendiendo a este Bando los falangistas en Sevilla, según el testimonio del Delegado de Propaganda de la Segunda División Militar, Antonio Bahamonde, recorrían las editoriales y librerías y todas las obras de autores que, según su criterio, eran de tendencia marxista, eran requisadas y destruidas allí mismo. Al comerciante tan sólo le daban la siguiente explicación: «La nueva España no admite esta literatura que ha envenenado tantos espíritus» ${ }^{25}$. Siguiendo el mismo mecanismo el teniente de la Guardia Civil y jefe de Orden Público en Córdoba desde el 22 de septiembre de 1936, Bruno Ibáñez Gálvez, en su primera actuación había requisado y destruido 5.544 libros. Por ello, trece días después de haber asumido el cargo, el 5 de octubre, afirmaba en El Defensor de Córdoba:

(...) Me encuentro satisfecho de haber llevado a cabo esta labor de limpieza moral, anunciando que la continuaré y que, en el caso de que agentes de mi autoridad encuentren en sus investigaciones algunas publicaciones de esta índole en librerías y kioscos, los dueños de los mismos serán sometidos a las más severas sanciones, aparte de cerrarles sus establecimientos. ¡Viva España! ${ }^{26}$.

De hecho en el periódico $A B C$ de Sevilla, diario afín a los sublevados, se incluía una nota el 26 de septiembre de 1936 de Ibánez Gálvez donde daba cuenta de la feroz campaña desatada en la capital cordobesa contra los libros pornográficos y revolucionarios:

Una de las cosas que más daño ha producido en la sociedad española, sobre todo en la juventud y en las masas obreras, ha sido la lectura de libros pornográficos y de propaganda revolucionaria, en especial la de autores rusos.

A tal descaro y profusión se había llegado en esto, que con dichas lecturas se había envenenado las almas puras de la juventud y la sencillez y nobleza de los obreros. Los puestos de honor en las librerías los ocupaban dichas publicaciones, que solo tenían por fin inculcar la rebeldía y el odio, así como relajar la moralidad y buenas costumbres de los espańoles: los resultados los estamos viendo, desgraciadamente, en los pueblos donde las hordas e indeseables marxistas actúan o han actuado.

En nuestra querida capital, al día siguiente de iniciarse el movimiento del Ejército salvador de España, por bravos muchachos de Falange Española fueron recogidos de kioscos

otros, VII Coloquio Nacional. Historia de la Educación, Tomo III: Educación Popular, Universidad de La Laguna, 1998, pp. 251-266.

25. Antonio Bahamonde, Un año con Queipo de Llano. Memorias de un nacionalista, Sevilla, Espuela de Plata, 2005, p. 129, (orig. de 1937).

26. Vid. Francios Moreno Gómez, La guerra civil...op. cit., p. 454. Y Francisco Asensio Rubio, «Bruno Ibánez Gálvez, de oficial de infantería a represor», en Espacio, Tiempo y Forma, núm. 24, 2012, pp. 195-228. 
y librerías centenares de ejemplares de esa escoria de la literatura, que fueron quemados, como merecían. Asimismo, muy recientemente, los valientes y abnegados Requetés realizaron análoga labor, recogiendo también otro gran número de ejemplares de esas malditas e insanas lecturas que deben desaparecer para siempre del pueblo español», [la cursiva es mía $]^{27}$.

Este aplicado represor insistía en la responsabilidad de las publicaciones disolventes en el estallido de la guerra porque sus ideas revolucionarias habían envenenado las almas de los jóvenes y de los obreros. Por este motivo justificaba la quema de esos textos tan peligrosos y elogiaba la actuación de los valerosos falangistas y carlistas en la desaparición de los mismos en los pueblos de España que iban ocupando. En su objetivo de limpiar Córdoba y su provincia de todo libro pernicioso y antipatriótico advertía que aquellas personas que no entregasen este tipo de publicaciones serían juzgadas con arreglo al bando militar. Además se instaba a los propietarios de librerías y kioscos que hubieran entregado libros y revistas de este tipo, que remitiesen una lista con el número y el título de todas ellas a dicha jefatura de Orden Público. Esta operación tan implacable de destrucción bibliográfica explica que el alcalde del pueblo cordobés, El Carpio, al finalizar la guerra comunicase a los responsables bibliotecarios que no era necesario el expurgo de títulos de la biblioteca municipal porque «la Autoridad Militar que se hizo cargo de todos los servicios de esta villa, cuando fue liberada por nuestro glorioso Ejército, ordenó la destrucción de la mayor parte de los volúmenes que existían, por ser todos los destruidos contrarios al ideal Nacional-Sindicalista, y otros de moral muy baja ${ }^{28}$.

En la biblioteca municipal de Dos Hermanas en Sevilla «bastantes libros, unos por rojos, otros por antirreligiosos, y otros por subidos de color, lascivos o verdes, simplemente por el nombre del autor, habían sido destruidos. Las autoridades del Alzamiento se habían desinteresado de la biblioteca, dado el ambiente enrarecido sobre el libro, para muchos el causante de la guerra y de la alteración de algunas cabezas poco asentadas», según señaló el bibliotecario y cofundador de la editorial Gredos, Hipólito Escolar, que hizo la guerra en el bando franquista ${ }^{29}$.

El ruido y la furia desatada contra las publicaciones afectaron a todas las bibliotecas de partidos y agrupaciones políticas, sindicales o culturales de las provincias andaluzas ocupadas por los militares. Así ocurrió en la provincia de Huelva como ha señalado Francisco Espinosa, destacando el caso de Valverde, donde desaparecieron dos importantes bibliotecas, la del Casino Republicano y la del Casino Obrero «La Alianza», contando con más de mil ejemplares la primera y quinientos la segunda. Muchos títulos se quemaron, otros pasaron a manos de particulares, e incluso de Falange, que se apropió del

27. $A B C$, Sevilla, 26 de septiembre de 1936, p. 17.

28. En Archivo General de la Administración (AGA), Sección de Educación, caja n 4752.

29. Hipólito Escolar, Gente del libro. autores, editores y bibliotecarios, 1939-1959, Madrid, Gredos, 1999, p. 11. 
Casino Republicano para cuartel y sede del Auxilio Social ${ }^{30}$. Igualmente merece especial atención la destrucción de la biblioteca de la Sociedad "La Cultura» Pro-Biblioteca Pública en Prado del Rey (Cádiz), recientemente estudiada por Fernando Romero, donde un tercio de los fondos catalogados fueron quemados en hogueras a las afueras del pueblo en 1936, y el resto se entregaron a la Central Nacional Sindicalista en 1940. Y al igual que en otros muchas localidades a la violencia desatada contra los libros se sumó la violencia contra los gestores e impulsores de este establecimiento creado en 1918 a iniciativa del carpintero Francisco Gutiérrez Ońate, conocido como Frasquito ${ }^{31}$.

En Navarra la quema de libros también fue un ritual frecuente tras el asalto a domicilios privados y a centros públicos. Al abogado Enrique Astiz Aranguren de Izquierda Republicana antes de asesinarlo le quemaron toda la colección de la "peligrosa» Enciclopedia Espasa, a pesar de estar impregnada de criterios católicos ${ }^{32}$. Había que acabar con «todos los libros, periódicos y folletos antipatrióticos, sectarios, inmorales, heréticos y pornográficos que han determinado un estado de corrupción y miseria en la conciencia moral de las masas», según constaba en la circular del 7 de noviembre de 1936 del Gobierno Civil de Pamplona ${ }^{33}$.

Incluso en la carta de súplica a las autoridades mexicanas solicitando asilo político, el mecánico José Puig Bosch, afirmaba desde el campo de concentración francés de Argelès-sur-Mer el 20 de abril de 1939: «Renuncio a volver a mi patria, según noticias de mis familiares, en un registro en mi casa han quemado más de cien libros (...) por el solo hecho de ser republicanos-federales toda nuestra vida y el no haber bautizado a nadie de dos generaciones», [la cursiva es mía] ${ }^{34}$.

Se desató una fobia contra La República del filósofo griego, Platón. Asimismo se incineró el título de Espasa-Calpe, Enciclopedia de la carne, aunque se trataba de un libro de gastronomía ${ }^{35}$. Sin embargo, en algunos casos la arbitrariedad y la ignorancia hacían que se salvasen libros más peligrosos. Así el bibliotecario del Círculo de Artesanos de La Coruña recordaba que se incineraron más de mil libros de la biblioteca, siendo pasto de las llamas Blasco Ibáńez, Ortega y Gasset, Pío Baroja, Marañón y Unamuno, aunque nunca supo por qué escaparon al fuego las obras de Voltaire, Rousseau y otros enciclopedistas franceses ${ }^{36}$.

30. Francisco Espinosa, La guerra civil en Huelva, Huelva, Diputación Provincial, 2005, p. 471.

31. Francisco Romero Romero, La Cultura y la Revolución.., op. cit..

32. Sorprende el ensañamiento con esta Enciclopedia ya que siguió valores católicos, de hecho casi la cuarta parte de los colaboradores eran eclesiásticos como demostró Philippe Castellano, Enciclopedia Espasa. Historia de una aventura editorial, Madrid, Espasa, 2000.

33. Navarra 1936. de la esperanza al Terror, Tafalla, Altafaylla, 2003, pp. 495 y 784.

34. En El País, 18 de noviembre de 2012. Esta carta se encuentra en el Archivo Histórico Diplomático de la Secretaría de Relaciones Exteriores mexicana.

35. Según testimonio del librero Enrique Moslit en Carlos Fernández Santander, Alzamiento y guerra civil en Galicia (1936-1939), A Coruña, Ediciós do Castro, 2000, Tomo I, pp. 101-102.

36. Ibidem, p. 90. 
A las pocas semanas del final de la guerra en Barcelona, el Ateneu Enciclopèdic Popular fue arrasado junto con los 6.000 volúmenes de su biblioteca. En la ciudad condal se destruyeron 72 toneladas de libros procedentes de editoriales, librerías, y de bibliotecas públicas y privadas. La biblioteca de Pompeu Fabra fue quemada en medio de la calle en Badalona, y la de escritor Rovira i Virgili desapareció junto a sus archivos. En Galicia fueron incautadas las bibliotecas de Alfonso Rodríguez Castelao, Bibiano Fernández-Ossorio Tafall y de Santiago Casares Quiroga. Más conocido es el pillaje sobre la biblioteca de Juan Ramón Jiménez en su casa madrileña de la calle Padilla por tres escritores falangistas, Félix Ros, Carlos Sentís y Carlos Martínez-Barbeito a principios de abril de 1939. También fue famosa la incautación de la biblioteca de Max Aub por parte de las autoridades franquistas y que acabó en los depósitos de la biblioteca de la Universidad de Valencia.

Tal fue el ensañamiento de los rebeldes en la destrucción de publicaciones que el que fuera Jefe del Servicio Nacional de Archivos, Bibliotecas y Propiedad Intelectual en el primer gobierno de Franco, Javier Lasso de la Vega, reconoció en un trabajo de 1942 que la Orden del 17 de agosto de 1938 estaba encaminada a regularizar la depuración, sustituyendo "la destrucción indiscriminada de libros por la creación de secciones de reservados y prohibidos ${ }^{37}$. En otros casos eran los propios propietarios los que se encargaron de quemar los libros para evitar represalias mayores, después de conocer lo que ocurría en los territorios conquistados por los militares. Así el periodista Eduardo Haro Teglen recordaba que la biblioteca de su padre desapareció en el fogón de su cocina ante la mirada implacable de su madre. No en vano su padre, Eduardo Haro Delage, marino retirado y periodista, fue condenado a muerte después de la guerra, aunque esta pena fue posteriormente conmutada por 30 años de cárcel:

Aquella biblioteca mía, aquella biblioteca de mi padre acabó como tantas otras, cuando llegaron los bárbaros y hubo que quemar libros antes de que quemasen también al lector. En mi casa había aquello que se llamaba "cocina económica», un gran fogón de hierro colado con varias bocas y un termosifón: cupieron grandes cantidades de libros malditos. Creo que algo lloré, y traté de salvar algunos de la mirada inflexible de mi madre, que tenía miedo. Sí, alguno quedó. Pero en los sucesivos registros de mi casa, nadie se fijó en los libros. Buscaban no sé qué otras $\operatorname{cosas}^{38}$.

En abril de 1938 se aprobó otra Orden para aplicar el contenido del Decreto de diciembre de 1936 sobre la declaración de ilicitud de la producción, comercio y circulación de material impreso pornográfico y disolvente a las obras procedentes del extranjero. Se estrechaba el círculo, el libro era siempre sospechoso y la mayoría de las veces culpable. Salvo una excepción, se autorizaban los libros, folletos y publicaciones periódicas doctrinales, impresos en alemán, italiano,

37. Javier Lasso de la Vega, "Concepto y misión de la biblioteca en el momento actual», en $\mathrm{La}$ clasificación decimal, San Sebastián, Editora Internacional, 1942, p. XLVII.

38. Eduardo Haro Teglen, «Libros para empezar una vida» en Biblioteca en guerra, Madrid, Ministerio de Cultura, 2005, p. 56. 
o portugués desde los años 1932, 1923 y 1926, respectivamente. Es decir, se permitía la entrada y circulación de libros editados por los regímenes fascistas de Europa: la Alemania nazi, la Italia de Mussolini y el Portugal salazarista ${ }^{39}$.

\section{DEPURACIONES DE FONDOS BIBLIOTECARIOS}

El 16 de septiembre de 1937 se promulgó una normativa sobre la formación de comisiones depuradoras de las bibliotecas públicas y centros de lectura en cada distrito universitario. Para ello, en primer lugar, se les exigía a los gobernadores civiles en el plazo de quince días una relación con todas las bibliotecas públicas, populares, escolares, así como las salas de lectura de casinos, sociedades recreativas, academias y de todo tipo de centros en cada provincia. En todos los distritos universitarios debían formarse comisiones depuradoras, presididas por el rector o un delegado suyo, y formada por un catedrático de la Facultad de Filosofía y Letras, un representante de la autoridad eclesiástica de la capital, un funcionario del Cuerpo de Facultativos de Archiveros y Bibliotecarios, un representante de la autoridad militar, otro de la Delegación de Cultura de FET de la JONS, y otro de la Asociación Católica de Padres de Familia. Las comisiones debían retirar aquellos

libros, revistas, publicaciones, grabados e impresos que contengan en su texto láminas o estampados con exposición de ideas disolventes, conceptos inmorales, propaganda de doctrinas marxistas y todo cuanto signifique falta de respeto a la dignidad de nuestro glorioso Ejército, atentados a la unidad de la Patria, menosprecio de la Religión Católica y de cuanto se oponga al significado y fines de nuestra Cruzada Nacional ${ }^{40}$.

Además de estas indicaciones se siguieron las recomendaciones de libros como el del religioso Pablo Ladrón de Guevara, Novelistas malos y buenos, publicado en 1910 por el Mensajero del Corazón de Jesús. En este libro, que tuvo una cuarta edición en 1933, se clasificaban los textos en heréticos, irreligiosos, impíos, blasfemos, clerófobos, anticlericales, malos, dañosos, peligrosos, inmorales, obscenos, provocativos, voluptuosos, sensuales e imprudentes, entre otros calificativos. Ladrón de Guevara justificaba la prohibición de libros por la Iglesia para evitar como "Madre amorisíma» la ruina de la fe y buenas costumbres de sus hijos ${ }^{41}$.

Estas comisiones provinciales, una vez analizados los fondos, debían enviar a la Comisión de Cultura y Enseñanza las listas con los títulos de las publicaciones que considerasen un peligro para los lectores. Después, esta Comisión examinaría los listados haciendo la siguiente clasificación: por un lado las obras pornográficas de carácter vulgar sin ningún mérito literario.

39. En Boletín Oficial del Estado 24 de junio de 1938.

40. En Boletin Oficial del Estado, 17 de septiembre de 1937.

41. Pedro Ladrón de Guevara, Novelistas malos y buenos, Bilbao, El Mensajero del Corazón de Jesús, 1933. 
Por otro las publicaciones destinadas a propaganda revolucionaria o a la difusión de ideas subversivas sin contenido ideológico de valor esencial. Y por último aquellos libros y folletos con mérito literario o científico, que por su contenido ideológico pudieran ser nocivos para los lectores «ingenuos o no suficientemente preparados para la lectura». Los dos primeros grupos serían destruidos sin dilación, mientras que el último permanecería guardado en los respectivos establecimientos en espacios restringidos. Estas obras sólo podrían ser consultadas con un permiso especial. A partir de entonces las salas con libros prohibidos empezaron a proliferar, los famosos «infiernos» en muchos establecimientos públicos. Estas salas especiales de obras reservadas fueron creadas por Orden de 17 de agosto de 1938 para completar la labor realizada por las Juntas depuradoras de bibliotecas en relación con la Orden del 16 de septiembre de 1937 anteriormente citada ${ }^{42}$. Los infiernos pervivieron durante toda la dictadura, así el infierno de la Biblioteca Pública de Oviedo no fue abierto al público hasta 1975.

Para realizar este expurgo se estableció un plazo improrrogable de dos meses pero, la imposibilidad de cumplirlo hizo que una Orden de 8 de junio de 1938 ampliara el plazo de actuación de las comisiones treinta días más. La Comisión Depuradora de San Sebastián en su informe sobre el expurgo de libros, según recogió Alicia Alted, señalaba que las producciones de Pío Baroja "constituyen uno de los más mortíferos venenos intelectuales», de Pérez Galdós afirmaba que "con su espíritu liberal y con su mal reprimido odio a la Iglesia, mayores estragos ha causado en la sociedad española del pasado siglo y todavía sigue causando", y del valenciano Blasco Ibañez decía "que con facultades extraordinarias de escribir ha realizado una labor demoledora e inmoral con todas las producciones ${ }^{43}$. Cabe destacar que la actuación de algunos rectorados en relación con las bibliotecas escolares fue anterior a la Orden de 16 de septiembre de 1937 como el de Valladolid, Zaragoza y Santiago de Compostela. El Rectorado de Valladolid, como cabecera de distrito universitario, decidió intervenir ante el cariz de la "propaganda antirreligiosa y antipatriótica» que se impartía en las escuelas y centros de enseñanza debido a las dimensiones «inconcebibles por su procacidad y descaro». Las directrices que dio este Rectorado el 21 de octubre de 1936 a todas las comisiones que se formaron en cada capital de provincia para examinar los fondos bibliográficos fueron las siguientes: se debían retirar o inutilizar todos los libros que figuraban en el Índice de la Congregación del Santo Oficio, los que fueran contrarios a la religión católica a la moral y a las buenas costumbres, aunque no se incluyesen en dicho Índice, aquellos que contemplasen propaganda del socialismo, comunismo, anarquismo y de la masonería, y por último los que directa o indirectamente atacasen a las unidad de la patria española. Ante la disyuntiva planteada por el Rector, sobre si los libros a eliminar debían ser ahogados o

42. En Boletín Oficial del Estado del 21 de agosto de 1938.

43. Alicia Alted, Política del nuevo estado sobre el patrimonio cultural y la educación durante la guerra civil, Madrid, Ministerio de Cultura, 1984, pp. 64-65. 
decapitados, el vicepresidente de la Comisión de Cultura y Enseñanza, Enrique Suñer, recomendó guillotinar los libros inservibles por su contenido.

La depuración de bibliotecas era una labor necesaria para el régimen de cara al futuro inmediato. El protocolo seguido era muy similar en todas las bibliotecas. Primero se procedía a la incautación de los fondos, después venía el expurgo de los títulos, seguían las hogueras con las obras más peligrosas y por último se creaban las secciones especiales con los libros menos peligrosos pero prohibidos a los lectores. Una vez concluido el proceso de purga y destrucción con las publicaciones existentes, se trataba de restringir la futura oferta con el establecimiento de la censura previa en la producción bibliográfica nacional y en la importación de títulos extranjeros.

En la Biblioteca Popular de Olot se retiraron numerosos títulos de carácter político y social, incluidos todos los escritos en catalán, independientemente de la temática. Después del expurgo los fondos del catálogo fueron revisados por el párroco-arcipreste de la localidad ${ }^{44}$. En Navarra se retiraron casi el $60 \%$ de los libros de las bibliotecas de Misiones Pedagógicas: de los 283 títulos analizados se rechazaron $166^{45}$. Sobre la importancia de la depuración de publicaciones destacaba la memoria de la Biblioteca Universitaria de Zaragoza correspondiente al año 1938, fechada el 20 de enero de 1939:

La revolución para infiltrar sus venenosas doctrinas en la sociedad, se sirvió del libro antipatriótico y antirreligioso en la escuela laica de la República y en otros Centros durante estos últimos años. Para destruir esta demoledora política y contribuir a la recta formación hispana, moral, religiosa y patria, el Excmo. Sr. Ministro de Educación Nacional, ordenó la depuración de las Bibliotecas escolares, de Misiones Pedagógicas, Circulantes, de Recreo, etc. retirando de ellos los libros inmorales, propaganda de doctrinas marxistas y todo cuanto signifique atentados a la unidad patria, menosprecio a la Religión católica y oposición al glorioso Movimiento Nacional ${ }^{46}$.

También la memoria de la Biblioteca Universitaria de Tarragona de 1939 insistía en estas cuestiones: "El expurgo de las Bibliotecas se imponía como una necesidad biológica si queremos que la victoria lograda por las armas no se vea amenazada por las ideas subversivas disparadas por esas publicaciones contrarias al espíritu que anima el glorioso Movimiento nacional ${ }^{47}$, [La cursiva es mía]. En este sentido desaparecieron muchos libros del catálogo de las bibliotecas como El asno de oro de Apuleyo, El libro de buen amor del Arcipreste de Hita, La

44. Jordi Canal i Morell, «Franquisme i repressió cultural. Les depuracions a la Biblioteca Popular d'Olot (1939-1940)", en L'època franquista. Estudis sobre les comarques gironines, Gerona: Cercle d'Estudis Històrics i Socials, 1989, pp. 109-124.

45. Véase el listado de libros censurados en las bibliotecas creadas por el Patronato de Misiones Pedagógicas en Reyes Berruezo Albéniz, Política educativa en Navarra 1931-1939, Pamplona: Gobierno de Navarra, 1991, pp. 156-163, y 263-268.

46. Véase la Memoria de la Biblioteca Universitaria de Zaragoza correspondiente al año 1938 (20-1-1939) en AGA, Sección de Educación, caja núm. 5459. Sobre la depuración de bibliotecas véase también en AGA, Sección de Educación, cajas núms. 4753, 4754 y 4755. Para el caso asturiano véase. el trabajo de Leonardo Borque López Bibliotecas, archivos y guerra civil en Asturias, Gijón: Trea, 1997.

47. AGA, Sección de Educación, caja núm. 5459. 
Celestina de Fernando de Rojas, El diablo mundo de Espronceda, La educación sentimental de Flaubert, Werther de Goethe, Artículos de costumbres de Larra, La rebelión de las masas de Ortega y Gasset, Papá Goriot de Balzac, Sonata de otoño de Valle-Inclán, Poesías completas de Antonio Machado, Nuestro padre San Daniel de Gabriel Miró, La hermana San Sulpicio de Palacio Valdés, El retrato de Dorián Gray de Oscar Wilde, Los miserables o Nuestra Señora de París de Víctor Hugo, Los pazos de Ulloa de Emilia Pardo Bazán, El fuego de Barbusse, Sin novedad en el frente de Remarque, Los siete ahorcados de Andreiev, Las almas muertas de Gógol, Crimen y castigo de Dostoyevski, Cómo enseña Gertrudis a sus hijos de Pestalozzi, Guerra y paz de Tolstói o Historia de la civilización española de Rafael Altamira. También perecieron todos los de Blasco Ibañez, varios títulos de Azorín y numerosos de Pérez Galdós y Pío Baroja, a pesar del libelo que escribió este último escritor sobre comunistas y judíos en la editorial Reconquista de Valladolid, dirigida por José Ruiz Castillo ${ }^{48}$.

En la nueva España todo lo que no fuera adhesión y defensa del Movimiento Nacional era considerado subversivo. Esta situación explica que no solo se acabara con libros contemporáneos de doctrina política, sino con obras de literatura de siglos pasados que nada tenían que ver con el comunismo internacional, una de las obsesiones del régimen. Muchos de los libros destruidos se convirtieron en pasta de papel, debido a la escasez de esta materia prima durante la guerra y, sobre todo, durante la posguerra. Este reaprovechamiento era más útil que convertir las páginas de los libros en cenizas, aunque menos vistoso y simbólico. Con este reciclaje se aprovechaban las hojas de los libros prohibidos para imprimir obras saludables y piadosas, acordes con el régimen nacionalcatólico. Así por un lado, era una forma más de aniquilamiento del pensamiento perseguido, y también una manera de que las voces calladas de esos libros volviesen a circular aunque convertidos en materia prima. Muchos de los libros de la España de Franco se hicieron sobre papel de libros condenados por inmorales y antipatrióticos. Con las incautaciones, expurgos y depuraciones de bibliotecas, editoriales, librerías y kioscos las autoridades franquistas querían acabar con toda la oferta bibliográfica existente en el mercado, a la vez que se establecía la censura previa para evitar reediciones y nuevas publicaciones subversivas o inmorales.

48. Aparte de los escritores mencionados también fueron censurados entre otros: Clarín, Miguel de Unamuno, Felipe Trigo, Eduardo Zamacois, Pérez de Ayala, Ramón J. Sender, D’Alembert, Condorcet, Voltaire, Rousseau, Alejandro Dumas, Bosch Gimpera, Eugenio Sue, Baudelaire, Zola, Anatole France, Gorki, Darwin, Charles Dickens, Nietzsche, Upton Sinclair, Sinclair Lewis, Schopenhauer, Freud o Marx. Sobre la depuración de las bibliotecas de Misiones Pedagógicas vid. José Andrés de Blas, «Algunos listados de libros depurados durante la guerra civil española en las bibliotecas escolares de Palencia (y Valladolid)», en Represura, http:// www.represura.es/, sección Documentación; «Un caso paradigmático de represión cultural: depuración de bibliotecas escolares en la provincia de Palencia durante la guerra civil española»; «El proceso de depuración...», op. cit. (1 ${ }^{a}$ parte); Carmen Diego Pérez, «Las Bibliotecas del Patronato de Misiones Pedagógicas en la provincia de Palencia: Dotación y depuración de sus fondos» (2. ${ }^{\text {a }}$ parte), en Represura, http://www.represura.es/, núm. 7, febrero de 2011. 
